\title{
Research on the University Library Alliance of China
}

\author{
Lei Yi \\ Library, Beijing University of Chemical Technology, Beijing, China \\ Email: 81058259@qq.com
}

How to cite this paper: Yi, L. (2020) Research on the University Library Alliance of China. Open Access Library Journal, 7: e6672.

https://doi.org/10.4236/oalib.1106672

Received: July 27, 2020

Accepted: August 17, 2020

Published: August 20, 2020

Copyright (C) 2020 by author(s) and Open Access Library Inc.

This work is licensed under the Creative

Commons Attribution International

License (CC BY 4.0).

http://creativecommons.org/licenses/by/4.0/

\section{(c) (i) Open Access}

\begin{abstract}
With the development of China's society and economy, especially entering the 21st century, the Chinese university library alliances (CULA) have made great progress, not only have built the China Academic Library \& Information System (CALIS), China Academic Social Sciences and Humanities Library (CASHL) such as national alliance organizations, but large-scale regional alliances in various provinces have also been established, and "Opening-up, Co-construction and Sharing" (OCS) has become the strong voice of the cooperation. The construction of CULA has gone through the stage of networking and digitization. With the continuous emergence of new information technologies, whether to use cloud computing, big data, artificial intelligence (AI), the internet of things, blockchain and other technologies to meet the increasingly professional, intelligent and personalized needs of readers is an important issue. It can be said that the development of CULA has reached an important stage where they can use emerging technologies to realize its own transformation and upgrading. This article will adopt the method of case analysis to study the construction ideas (CI), organizational structure (OS), and operation methods (OM) of the CULA.
\end{abstract}

\section{Subject Areas}

Library, Intelligence and Philology

\section{Keywords}

Chinese University Library Alliances (CULA), China Academic Library \& Information System (CALIS), China Academic Social Sciences and Humanities Library (CASHL), Artificial Intelligence (AI)

\section{Introduction}

The library alliances (LA) refer to the cooperative community established be- 
tween libraries with the functions of joint consulting, group procurement, interlibrary loan, document delivery, and business training (Yi, 2014) [1]. The university library alliance (ULA) is an important type of LA. With the continuous deepening of reform and opening up, especially in the 21 st century, with the vigorous development of China's society and economy, the OCS has become the strong voice of the cooperation. Great progresses have been made, not only have national alliance organizations such as China Academic Library \& Information System (CALIS) and China Academic Social Sciences and Humanities Library (CASHL) established (Yang, 2008) [2], but large regional alliances in various provinces have also been set up. Now, the construction of the CULA has gone through the stage of networking and digitization. With the continuous breakthroughs of emerging information technologies, it can be realized to use emerging information technologies such as cloud computing, big data, AI, internet of things and blockchain to meet the readers' increasingly professional, intelligent, and individualized needs, which is an important issue (Su, et al., 2020) [3]. It can be said that the CULA has now reached an important stage where they can use emerging technologies to achieve its own transformation and upgrading.

\section{The situation of CULA}

\subsection{Several National Alliances Have Been Established}

CALIS and CASHL are the development models of the CULA in the past two decades, especially CALIS has played a great role in promoting the development of ULA in China (Yang, 2008) [4]. Just under the direct influence of CALIS, China has not only built the Digital Resource Acquisition Alliance of Chinese Academic Libraries (DRAA) and Federation of China Academic Institutional Repository (CHAIR), but promoted the construction of regional alliances among provinces. (Chen, 2018) [5].

\subsubsection{China Academic Library \& Information System}

CALIS is the largest ULA in the world, which has 1800 registered member libraries, covering 31 provinces (autonomous regions and municipalities) of China. CALIS was formally established and designed online cooperative cataloging system in 1998. At the same time, it is also the pioneer of group purchasing in China. As the infrastructure of UL sharing and public service, CALIS has built an open, distributed and multi library cooperation platform (Wang, 2005) [6]. Its document delivery service network was officially launched in June 2004, based on the collection resources of all member libraries, which provides interlibrary loan and document delivery services (Wang, Cai \& Dong, 2013) [7]. Since then, university readers can access the rich collections of other university libraries in a convenient and quick way.

\subsubsection{China Academic Social Sciences and Humanities Library}

CASHL was officially launched and began to provide services in 2004 (Liang, et al., 2015) [8], which has 830 member libraries, and is center of the humanities 
and social sciences document collection in China. It currently has 26,490 core journals and important printed journals in the field of foreign humanities and social sciences, 2739 electronic journals, more than 730,000 electronic books, and more than 2 million foreign printed books. It mainly provides services such as database retrieval, interlibrary loan, and original text delivery (Liu, 2006) [9].

\subsubsection{Digital Resource Acquisition Alliance of Chinese Academic Libraries}

The DRAA was jointly initiated and established by some member libraries of CALIS, aiming to seek the best price and service for member libraries in terms of digital academic resource procurement through group procurement (Zhao, et al., 2015) [10]. The work of the alliance mainly includes: database evaluation, organization of experts for database negotiation, group procurement plan review and release, organization of training, group procurement agent selection, database vendor and agent after-sales service supervision, etc. (Xu, et al., 2019) [11]. In terms of database evaluation, experts are mainly invited by the lead pavilion of the alliance to form a group procurement database negotiation team, and carry out the pre-and post-evaluation work of the database group procurement based on the trial and use conditions.

\subsubsection{Confederation of China Academic Institutional Repository}

The CHAIR was co-sponsored and established by some member libraries of CALIS, which aims to promote the construction of the national university institutional repository, promote the open access of academic achievements, and promote the wide application of academic achievements. The main tasks of the alliance include: carrying out investigations and studies on alliance construction and development related policies, formulating corresponding policies, and developing institutional knowledge base platform systems, data and service-related standards and specifications.

\subsection{Regional Alliances in the Ascendant}

Information technology plays a vital role in promoting the rapid development of the LA. In the past 20 years, alliances based on "digital libraries" (DL) or "sharing systems" (SS) have been the main feature of the regional alliances development of Chinese academic libraries.

\subsubsection{Alliances Based On the DL}

As electronic resources account for an increasing proportion of university literature resources, the construction of alliances based on the DL has become the mainstream of CULA. All provinces in China have basically established their own digital libraries for colleges and universities. For example, Hebei Province has the "Hebei Academic Digital Library Alliance (HADLA)", Jiangsu Province has the "Jiangsu Academic Library Information System (JALIS)", and Zhejiang Province has "Zhejiang Academic Digital Library (ZADL)”, and so on. 
Table 1. Representatives of Regional ULA based on DL in China.

\begin{tabular}{cccc}
\hline Alliance name & Management Center & Founded time & $\begin{array}{c}\text { Number } \\
\text { of member }\end{array}$ \\
\hline JALIS & Nanjing University Library & 1997 & 175 \\
HADLA & Yanshan University Library & 2002 & 54 \\
Tianjin Academic Library \& & Tianjin Polytechnic & 2004 & 60 \\
Information System (TALIS) & University Library & & 38 \\
Hunan University & Hunan Normal \\
Digital Library & University Library & 2004 & 80 \\
ZADL & Zhejiang University Library & 2008 & 104 \\
Anhui Academic Digital Library & University of Science and & 2009 & 52 \\
Technology of China Library & & & \\
Fujian Academic Digital & Fuzhou University Library & 2011 & 68 \\
Jiangxi Province Academic & Jiangxi Normal & 2012 & \\
Digital Library & University Library & & \\
\hline
\end{tabular}

Table 1 shows the representatives of regional ULA based on DL in China. JALIS officially launched in 1997, which is Jiangsu document information service center and also Northeast China regional center of CALIS. HADLA located in Yanshan University was approved by the Hebei Provincial Department of Education in January 2002 and issued a document to start the construction ( $\mathrm{Yi}$, et al., 2017) [12], which is responsible for organizing the construction and service of document information in Hebei Province, and as the Provincial Center of CALIS was approved in June 2005. TALIS is an entity rebuilt from the original "Tianjin University Digital Library Construction Management Center" in November 2004 after the approval and issuance of documents by the Tianjin Education Commission (Yi, et al., 2017) [12]. The center was approved as the Tianjin Center of CALIS in 2004, and is responsible for organizing the construction and service of document information in Tianjin.

In general, the construction ideas (CI), organizational structure (OS), and operation methods (OM) of UDL in all provinces are basically the same. Here, we take ZADL as an example to briefly analyze the CI, OS, and OM of the regional alliances of academic libraries in various provinces in China. ZADL's CI is to rely on CALIS and use advanced DL technology as a means to provide a full range of document guarantee services for teaching, scientific research and key discipline construction in Zhejiang colleges and universities. In terms of organizational structure, ZADL project service center has a secretariat and three professional working teams (service, resource, technical), which are responsible for the coordination of project debriefing and daily management. ZADL management center (MC) is responsible for the specific implementation of the project, the custody and operation of daily services, and the maintenance of the system platform. Its office is located in the Zhejiang University Library. ZADL submitted 33 special 
resource database construction projects to Zhejiang Provincial Department of Education and Department of Finance for approval in two batches. Among the 33 characteristic resource databases, 18 are about the school's characteristic subjects, 6 are about local history and culture, 6 are about celebrity research. It is one of the highlights of ZADL's characteristic resource database to combine local characteristic history and culture with the school's characteristic disciplines (Wang, 2013) [13]. ZADL has opened unified search, reference consulting, interlibrary loan and other application systems, and seamlessly integrated resource acquisition methods (Gao, et al., 2013) [14]. It has established a relatively complete digital document resource protection system, which can provide services for millions of teachers and students in nearly 80 colleges and universities in Zhejiang Province.

\subsubsection{Alliance Based on SS}

The rapid development of network technology has greatly reduced the cost of human resources, material, and financial resources, which has also provided powerful tools for in-depth cooperation between academic libraries, especially relying on network tools (Yi, 2014) [1]. The established SS is one of the indispensable infrastructures for the integration of resources between libraries. Alliances based on SS often rely on a system platform and use a convenient network to provide readers with services such as original text delivery, interlibrary loan, and information consultation (Yi, 2014) [1]. Beijing Academic Library \& Information System (BALIS) is a typical representative of this type of alliance, which is one of the higher education public service systems in Beijing under the leadership of Beijing Education Commission. Its purpose is, under the leadership of the Beijing Education Commission, to integrate national investment, modern library concepts, advanced technology, and the rich literature resources and human resources of colleges and universities to build a joint guarantee system for Beijing higher education documents, relying on CALIS realizes the openning-up, co-construction and sharing of document information resources to maximize social and economic benefits, serving Beijing's higher education, and serving Beijing's economic and social development (Yi \& Lin, 2013) [15]. "Tianjin ULA" is another representative of this type of alliance. In 2003, $17 \mathrm{mu}$ nicipal undergraduate college libraries in Tianjin realized the goal of sharing a set of software, a server, and a central database through the Unicorn Consortia joint system. Since then, the circulation, editing, and system staff of the 17 colleges and universities have been on this platform (Yi, et al., 2017) [12].

\section{The Development Characteristics of CUL A}

\subsection{Combination of Centralized Management and Decentralized Services}

CALIS has established a service network with a three-level document information assurance model of "national center, regional center, and university li- 
brary", which is responsible for resource coordination and joint construction, document information sharing services, and staff training and Reader training, application system construction, etc. CALIS has established four national literature information centers in Beijing, including arts and sciences, engineering, agronomy, and medicine, which form the core of the three-tier structure and mainly serve as a base for document information assurance (Feng \& Gao, 2013) [16]. Among them, the two national centers for liberal arts and engineering are located at Peking University and Tsinghua University; the two national centers of agronomy and medicine are located in China Agricultural University and Peking University Medical Department.

CASHL is composed of a project MC, 2 national centers (NC), 7 regional centers (RC), and 8 discipline centers (DC). Its responsibilities are to collect resources systematically and provide services effectively. The specific responsibilities of each center are as follows: CASHL MC is located in Peking University Library, responsible for overall resource construction and service planning. The CASHL NC is located in Peking University and Fudan University, which is responsible for the overall planning, construction and service of resources, collecting printed journals and electronic resources, providing data on the collection of foreign humanities and social science journals of the university, and cooperating with the CASHL MC to carry out data processing work and maintain local documents. The CASHL RC are located in 7 universities including Wuhan University, Jilin University, Sun Yat-sen University, Nanjing University, Sichuan University, Beijing Normal University, Lanzhou University, and assist the national center in the overall planning, construction and service of resources, as well as collection of printed journals and electronic Resources, provide the school's foreign humanities and social sciences journal collection data, cooperate with the CASHL MC to carry out data processing, maintain the local document delivery service system, and focus on the region and the school to provide services. CASHL DC is located in 8 universities, including Northeast Normal University, East China Normal University, Nankai University, Shandong University, Tsinghua University, Xiamen University, Zhejiang University, and Renmin University of China. Its main responsibility is to plan and collect electronic resources, provide the school's foreign humanities and social science journals collection data, cooperate with the CASHL MC to carry out data processing, maintain the local document delivery service system, and cooperate with the NC and RC to provide services (Yang, 2008) [2].

BALIS has six centers for original text delivery, interlibrary loan, joint consulting, resource coordination, training, and technical support. Table 2 shows the six sub-centers of BALIS. A combination of centralized management and decentralized services is adopted to meet readers' literature needs. The BALIS MC office is located in the library of Renmin University of China, which is responsible for the organization and implementation of the management coordination, and supervision and inspection (Yi, et al., 2017) [12]. 
Table 2. The 6 sub-centers of BALIS (Yi, et al., 2017) [12].

\begin{tabular}{|c|c|c|}
\hline Sub-center & In charge & Main work \\
\hline Original text delivery $\mathrm{MC}$ & $\begin{array}{l}\text { Renmin University of } \\
\text { China Library }\end{array}$ & $\begin{array}{l}\text { Coordinate the original delivery } \\
\text { service between member libraries }\end{array}$ \\
\hline Interlibrary loan MC & $\begin{array}{c}\text { Beijing University of Posts } \\
\text { and Telecommunications } \\
\text { Library }\end{array}$ & $\begin{array}{l}\text { Coordinating the interlibrary loan } \\
\text { service among member libraries }\end{array}$ \\
\hline $\begin{array}{l}\text { Resource coordination } \\
\text { center }\end{array}$ & $\begin{array}{l}\text { Capital Normal } \\
\text { University Library }\end{array}$ & $\begin{array}{l}\text { Coordinate the group purchasing of } \\
\text { the database by the member libraries }\end{array}$ \\
\hline Training center & $\begin{array}{l}\text { Beijing Normal } \\
\text { University Library }\end{array}$ & $\begin{array}{c}\text { Coordinate business training and technical } \\
\text { learning of member libraries }\end{array}$ \\
\hline $\begin{array}{l}\text { Joint Information } \\
\text { Consulting Center }\end{array}$ & $\begin{array}{l}\text { Beijing University of } \\
\text { Science and Technology } \\
\text { Library }\end{array}$ & $\begin{array}{l}\text { Coordinate scientific and technological } \\
\text { novelty search and information consulting } \\
\text { services among member libraries }\end{array}$ \\
\hline Technical support center & $\begin{array}{l}\text { Tsinghua University } \\
\text { Library }\end{array}$ & $\begin{array}{l}\text { Provide information technology guarantee } \\
\text { for the development of BALIS }\end{array}$ \\
\hline
\end{tabular}

TALIS has established a leading team to be responsible for the DL construction project. Its main responsibility is to formulate development strategy and provide policy support. Secondly, there is "a Resource Construction Committee" under the team, which is responsible for the procurement and maintenance of digital resources. Finally, in order to facilitate work, it has set up seven working teams under the leading team, each responsible for specific business operations, as shown in Table 3. The main responsibilities of these seven working teams are very similar to the main functions of the five sub-centers of BALIS.

Table 3. The Main Responsibilities of the 7 TALIS working Teams (Yi, et al., 2017) [12].

\begin{tabular}{|c|c|}
\hline Team name & Main duty \\
\hline System Support Team & $\begin{array}{l}\text { Mainly responsible for the maintenance, debugging, management } \\
\text { and training of the automation system of Tianjin University Library }\end{array}$ \\
\hline Technical Support Team & $\begin{array}{c}\text { Mainly responsible for the maintenance of Tianjin UL network } \\
\text { and the application of computer technology }\end{array}$ \\
\hline Cataloging Team & $\begin{array}{c}\text { Mainly responsible for the data cataloging of the central system } \\
\text { and the management of cataloging data }\end{array}$ \\
\hline $\begin{array}{l}\text { Document Delivery and } \\
\text { Interlibrary Loan Team }\end{array}$ & $\begin{array}{l}\text { Mainly responsible for coordinating the document delivery } \\
\text { and interlibrary loan between Tianjin university libraries }\end{array}$ \\
\hline Information Services Team & $\begin{array}{l}\text { Mainly responsible for various information } \\
\text { services and consulting }\end{array}$ \\
\hline $\begin{array}{l}\text { Academic Research and } \\
\text { Exchange Team }\end{array}$ & $\begin{array}{l}\text { Responsible for carrying out scientific research exchange activities } \\
\text { in library science, information science and other majors }\end{array}$ \\
\hline Skills Competition Team & $\begin{array}{l}\text { Responsible for the organization of the knowledge } \\
\text { and skill competition of university libraries }\end{array}$ \\
\hline
\end{tabular}




\subsection{The Government Provides Policy, Financial Support and Project-Based Operation}

The CULA have been developed under the strong support of the government. The government's support is mainly reflected in two aspects: one is financial support. Judging from the established ULA in China, most of them are funded through the projects of education authorities. For example, CALIS is a public service infrastructure for all academic libraries invested and constructed in the project of the Ministry of Education of China, which officially started construction in November 1998, As of 2012, has invested a total of 352 million yuan to build the online cataloging system, the document discovery and acquisition system, the collaborative service system and the application software cloud service platform, etc. BALIS supports its own development based on the projects approved by the Beijing Municipal Education Commission (BMEC). The second is policy support. Policy support provides the necessary environment for the alliance to formulate unified system standards and feasible management plans. TALIS and HBADLA also adopt a project-based mode of operation, and their funding bodies are the Tianjin Municipal Education Commission and the Hebei Provincial Education Commission respectively. ZADL adopts a project management system, and the ZADL MC determines the sub-projects to be constructed according to the construction plan approved by the Zhejiang Provincial Department of Education (ZPDE). The ZADL MC organizes the application for the establishment of ZADL construction sub-projects every year, and at the same time inspects the construction of the sub-projects in the previous year. On the basis of university application, expert review, and provincial education department's approval, the ZPDE formally determined the sub-projects to undertake. After the implementation of the ZADL sub-project, the ZADL MC will be responsible for the process management, performance appraisal, follow-up service and other daily work of the sub-project (Gao, 2011) [17]. ZADL sub-project construction universities accept the management and supervision of the ZADL MC.

\section{Development Trend of CULA}

\subsection{Building Smart Library}

At present, the construction of ULA in China pays close attention to two major directions, one is the intelligent management and service, the other is the construction of cloud service platform. With the continuous development of AI technology, the intelligent level of ULA in dealing with big data of literature is bound to be higher and higher. The construction of Smart Library (SL), based on AI technology, provides readers with more professional and intelligent personalized services, which is the development trend of the L A in the future (Chu \& Duan, 2018) [18]. The construction of SL is to realize the intellectualization of the whole library management and service. Through a variety of sensors (radio frequency technology) to collect personnel exchanges, reader borrowing, litera- 
ture download and other information, and then transmitted to the cloud big data center, and then through the AI system, to provide targeted services for readers, greatly improving the use efficiency of database and paperboard books. The key to the construction of SL is to realize the whole process quality traceability of reader services. This process includes intelligent screening, intelligent pushing and intelligent borrowing of high-quality databases. The purpose of this process is to improve the management and service efficiency of the library by realizing the intelligent perception, intelligent service and intelligent analysis of the reading environment of the library.

\subsection{Building Cloud Library}

With the continuous enrichment of library collection resources and the continuous expansion of service connotation and extension, the traditional integrated management system based on paper resource management has been unable to meet the needs of the readers. It is inevitable to develop the library platform facing the future. In the era of AI, another type of ULA-Cloud Library (CL) will become the leading role (Shen, 2020) [19]. CL is an important direction of the development of ULA in the future. Its essence is a cloud platform with big data processing, AI and other technologies as the core. JALIS phase IV mainly relies on university informatization and big data center to provide resources and services for university readers in Jiangsu Province. It is a unified, integrated, distributed, open, multi-level and personalized "cloud service platform of University Digital Library in Jiangsu Province" to adapt to the development of university informatization and big data technology. The service of Fujian Provincial University Digital Library has changed to "knowledge center", "Learning Center" and "exchange center" for teachers and students in Fujian Province. CALIS will create a new ecology of library information construction by building a developer alliance that information technology enterprises, libraries and personal development enthusiasts participate in, and jointly develop new systems and applications based on unified standard and unified platform (folio) (Wang, Chen \& Guan, 2020) [20]. CALIS will build a new generation of library service platform (CLSP) based on folio in the next few years. Its core elements are: five openness (open and unified micro service architecture, open central knowledge base, open multi-level platform services, open and inclusive ecology, open and diversified applications) + 5 standards (platform standardization, data standardization, service standardization, app development standardization, and community management standardization).With the development of new technologies such as AI, $5 \mathrm{G}$ and virtual reality, the new generation of ULA will be driven by AI. In the era of big data, CL adopts cloud computing technology to integrate scattered data resources and provide services through a unified cloud platform, which centralized procurement of database resources of various publishing types and disciplines in the world, supporting the rapid upload and preservation of various types of academic achievements, and supporting the high level of massive resources 
sharing enables libraries and users in different regions and types in China to enjoy stable, efficient and unrestricted information services.

\section{Conclusion}

To serve the development of China's higher education, to track the new heights of global scientific research information, and to provide a strong guarantee of literature resources for the development of Chinese higher education are the basic tasks of the construction of CULA. There is no doubt that information technology plays an important role in the construction of ULA in China. The continuous development of information technology is one of the main reasons to promote the continuous upgrading of ULA construction. In the era of "network and digitization", the construction of CULA has completed three aspects of work: one is to basically realize the digitization of literature resources; the other is to basically construct the sharing platform of literature resources; the third is to basically realize the interconnection between member libraries. With the wide application of artificial intelligence technology, the construction of ULA in China has come to an important stage of transformation and upgrading by using emerging technologies. At the present stage in China, only by relying on AI can we achieve overtaking on the curve and overtake the service level of the world-class ULA. "Opening-up, Co-construction and Sharing" has become the strong voice of ULA Cooperation in China. In the era of AI, it is an inevitable trend to pay attention to the intelligence, specialization and personalization of service.

\section{Conflicts of Interest}

The author declares no conflicts of interest regarding the publication of this paper.

\section{References}

[1] Yi, L. (2014) Consideration on the Development of China's University Library Regional Consortiums: A Case of BALIS. Library Work in Colleges and Universities, No. 3, 53-55.

[2] Yang, J.H. (2008) Comparative Research of the Delivery Systems of CALIS and CASHL. Information and Documentation Services, No. 5, 51-56.

[3] Su, B., et al. (2020) Research on the Construction of National Digital Academic Information Resources Guarantee Consortium Based on Cloud Computing. Library Work and Study, No. 2, 5-11.

[4] Yang, J.H. (2008) The Analysis and Comparison of the Relationships between the Two Document Delivery Systems of CALIS and CASHL. Library Development, No. 11,1 .

[5] Chen, L. (2018) CALIS 20 Years: From Co-Construction and Sharing to Integration and Openness. Digital Library Forum, No. 12, 1.

[6] Wang, Y. (2005) CALIS Union Catalog System. New Technology of Library and Information Service, No. 7, 18-21. 
[7] Wang, Y., Cai, L.N. and Dong, Z. (2013) CALIS and Library Construction. Digital Library Forum, No. 1, 68-76.

[8] Liang, Y.N., et al. (2015) Study on the Situation and Development of CASHL. Journal of Academic Libraries, No. 6, 72-77.

[9] Liu, Z.H. (2006) CASHL Is a Successful Mode of Information Resources Sharing in China. Journal of Academic Libraries, No. 5, 7-10.

[10] Zhao, et al. (2015) Research on Distribution and Cooperation Strategy of DRAA University Libraries Members. Modern Information, No. 12, 128-133.

[11] Xu, et al. (2019) Study on the Long-Term Preservation and Usage of DRAA Introduced Digital Resources. Journal of Academic Libraries, No. 6, 70-77.

[12] Yi, L., et al. (2017) How to Construct the Beijing-Tianjin-Hebei University Library Consortium under the Background of Regional Integration. Library Journal of Henan, No. 3, 63-64.

[13] Wang, Q. (2013) Review on the Construction of Special Resource Databases of Zhejiang Academic Digital Library. Library Development, No. 1, 29-31.

[14] Gao, Y.X., et al. (2013) Study on the Service Model of Regional Document Delivery Network Based on Resources Integration-Taking ZADL Document Delivery Network as an Example. Library, No. 2, 82-84.

[15] Yi, L. and Lin, H.T. (2013) Analysis on Major Problems and Countermeasures of BALIS Document Delivery. Modern Information, No. 2, 72-74.

[16] Feng, Y. and Gao, B.J. (2013) CALIS Services and the Principles of Designing CALIS Services. Digital Library Forum, No. 1, 21-28.

[17] Gao, Y.X. (2011) Research on Operational Mechanism for Information Resource Sharing of Regional Academic Libraries. Information Research, No. 1, 70-73.

[18] Chu, J.L. and Duan, M.Z. (2018) Smart Library and Smart Services. Library Development, No. 4, 85-90.

[19] Shen, Y. (2020) The Design and Realization of Intelligent Robot in Library: A Case Study of Digital Library Experience Area in National Library of China. Library, No. 6, 37-41.

[20] Wang, W.Q., Chen, L. and Guan, T. (2020) Integrated Development of CALIS New-Generation Library Service Platform. Digital Library Forum, No. 1, 2-10. 